\title{
Random Walker Test: A computerized alternative to the Road-Map Test
}

\author{
Hiroyuki Uchiyama, Kohsei Mitsuishi, ANd Hiroshi OhNo \\ Kagoshima University, Kagoshima, Japan
}

\begin{abstract}
The Road-Map Test (RMT) is a popular neurological assessment of left-right orientation, using a simplified road map. Inspired by the RMT, we developed a new computerized navigation test, the Random Walker Test (RWT), for further quantitative assessment of left-right orientation ability. RWT provides verbal or nonverbal instructions for the direction (left, right, or front) in which to proceed, and participants must judge the spatially correct direction. Perspectives rotate by $90^{\circ}$ during navigation. Verbal judgments demand verbal-to-spatial mapping of left/right/front and, if necessary, egocentric perspective rotation. Using the RWT, we evaluated the left-right orientation of normal male participants. The RWT reliably recorded the response times and error rates for participant performance and also revealed egocentric perspective rotation as an unreliable mental process with large intra- and interpersonal variability. These results indicate that the RWT may be useful in investigating left-right orientation and/or egocentric perspective rotation in both normal participants and neuropathological patients.
\end{abstract}

Languages are means of communication, and human communication includes spatial relations between objects in the environment (Bloom, Peterson, Nadel, \& Garrett, 1996; Chatterjee, 2001; Kemmerer, 2006). Spatial relations are thought to be processed using two independent subsystems (coordinate and categorical) in the human brain (Jager \& Postma, 2003; Laeng, Chabris, \& Kosslyn, 2003). Categorical spatial relations are processed predominantly in the left cerebral hemisphere and are represented by words that specify binary oppositions, such as in/out, left/right, above/below, and front/back (Kosslyn, 1987; Laeng \& Peters, 1995). Left and right are unique among these categorical spatial words, because of their dependency on the frame of reference and for the reasons described below. Frames of reference are coordinate systems used to compute and specify the locations of objects with respect to other objects.

Recent studies by Levinson and his colleagues have revealed a large variation in the usage of frames of reference among cultures (Haun, Call, Janzen, \& Levinson, 2006; Haun, Rapold, Call, Janzen, \& Levinson, 2006; Majid, Bowerman, Kita, Haun, \& Levinson, 2004). They identified a close relationship between languages spoken and usage of frames of reference. Participants who speak European languages use an egocentric frame of reference for spatial reasoning problems on the horizontal plane, whereas participants who speak other languages, such as Tzeltal, use a geocentric frame of reference. The Japanese language is quite similar to European languages with respect to preferences for frames of reference (Kita, 2006), despite being linguistically very different from European languages. The argument has been made that language and culture mask the native tendency to use the geocentric frame of reference (Haun, Call, et al., 2006). One-yearold infants prefer to use the allocentric reference frame, but 3-year-old German-speaking children prefer to use the egocentric frame of reference (Haun, Rapold, et al., 2006). Children do not simply map local forms into preexisting innate concepts but build those concepts as they learn their own language (Levinson \& Wilkins, 2006).

Left and right represent key descriptors for verbalspatial mapping in the egocentric frame of reference. In accordance with the findings of Levinson and his colleagues, the concept of left-right has not been shown to be instinctively acquired. Instead, a relatively long learning process in infancy and childhood is needed, and most young children often confuse left-right orientation (Dellatolas, Viguier, Deloche, \& De Agostini, 1998; Money, Alexander, \& Walker, 1965; Rigal, 1994, 1996). Some adults also admit to some difficulty with left-right orientation (Storfer, 1995; Wolf, 1973). Left-right orientation is thus thought to have large interpersonal variations even in intellectually normal/above-normal populations.

Apart from naturally occurring interpersonal variation in left-right orientation, neurological and neuropsychological studies have revealed that patients with particular cerebral disorders show severe deficiencies in left-right orientation. These disorders include Gerstmann's syndrome (caused by damage localized to the left angular gyrus of the parietal cortex; Gold, Adair, Jacobs, \& Heilman, 1995; Mayer et al., 1999), Turner's syndrome (caused by a congenital abnormality; Nijhuis-van der Sanden, Eling, \& Otten, 2003), and Alzheimer's disease (Rainville, Marchand, \& Passini, 2002). These studies may provide

H. Uchiyama, uchiyama@ibe.kagoshima-u.ac.jp 

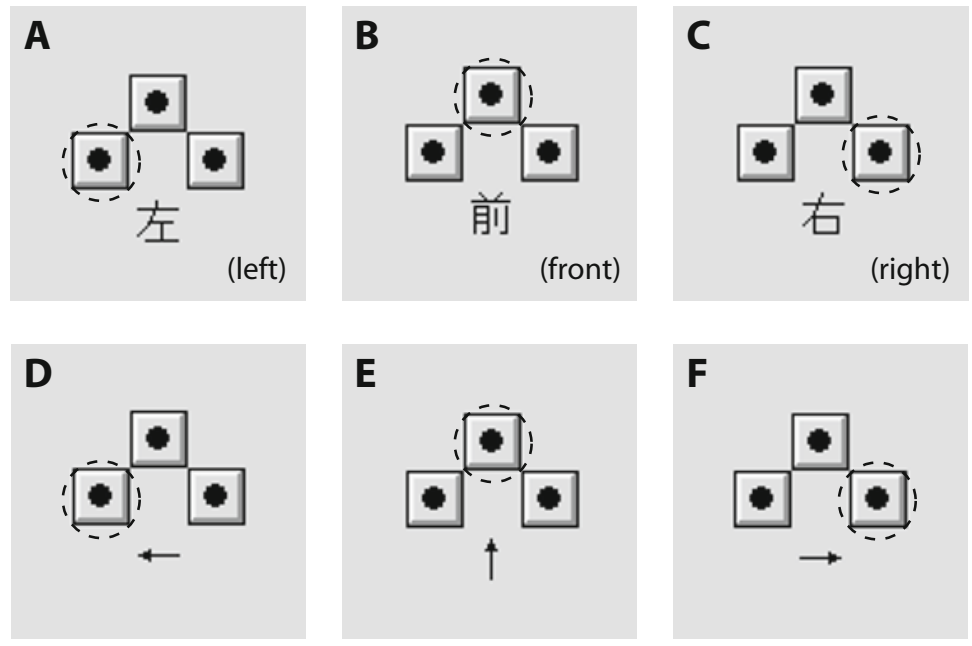

Figure 1. Screen-capture images of areas, including three graphical-userinterface buttons and an instruction for the direction in which to proceed, in the RWT windows. Correct buttons are indicated by broken-line circles (not shown on screen). (A-C) Verbal instructions presented by the Japanese kanji characters denoting left (A), front (B), and right (C). (D-F) Nonverbal instructions presented by graphical arrows oriented orthogonally.

important clues to understanding the neural systems involved in left-right orientation (Kemmerer, 2006).

The Road-Map Test (RMT) has been widely used to measure left-right orientation, primarily for neurological diagnosis of patients (Money et al., 1965). Participants state which direction the examiner has turned at each of 32 intersections, while the examiner follows a route indicated by a dotted line on a road map. RMT is primarily designed to measure correctness of judgments, not reaction times (RTs). Being limited to only 32 samples for each participant and the inability to measure RTs precisely are weaknesses for the quantitative assessment of left-right orientation ability.

Inspired by the RMT, we developed a new computer program, the Random Walker Test (RWT), for further quantitative assessment of left-right orientation ability. Left-right orientation in the RWT demands egocentric perspective rotation, if necessary, from participants (as with the RMT), as well as verbal-to-spatial mapping of left-right to a particular direction of the egocentric frame of reference. Using the RWT, left-right orientation was quantitatively evaluated in right-handed male university students. The aim of this study was to show that the RWT can be used as a quantitative alternative to the RMT.

\section{METHOD}

\section{Participants}

Because the left-right orientation ability is known to have large interpersonal variations, as was described above, participants in the present study were selected from a relatively homogeneous population in order to limit the sources of incomprehensible variations in the data. The participants consisted of male Japanese junior students in the Department of Information and Computer Science, Faculty of Engineering, Kagoshima University. All the participants had normal eyesight. The RWT was performed in partial fulfillment of a laboratory work credit. The HN Handedness Inventory (Hatta \& Nakatsuka, 1976) was used for quantitative identification of handedness. This inventory resembles the Edinburgh Handedness Inventory and was adjusted exclusively for Japanese participants. Scores for the HN Handedness Inventory range from -10 (extreme lefthandedness) to 0 (equally mixed handedness) to 10 (extreme righthandedness). Thirty-eight male participants with HN Handedness Inventory scores of 8-10 were classified as right-handers and were selected for further analyses. Nine male participants with HN Handedness Inventory scores ranging from -10 to 7 were classified as non-right-handers, and their data were classified as reference data.

\section{Equipment}

The experiment was performed using a Macintosh G3 computer (Apple Computer Japan, Tokyo, Japan) and an LCD monitor (18.1 in.; Sharp, Tokyo, Japan). MATLAB 5.2.1 (The MathWorks, Natick, MA) and the RWT program codes written in MATLAB language were installed on the computer. The RWT program was executed using the MATLAB interpreter. The distance between the participant and the monitor was approximately $40 \mathrm{~cm}$.

\section{RWT}

The program codes of the RWT utilize the built-in "uicontrol" facilities of MATLAB. In the RWT, the participant is asked to follow computer-generated verbal or nonverbal instructions for the direction in which to proceed (left turn, right turn, straight ahead) and to click one correct graphical-user-interface (GUI) button out of three available buttons, using a computer mouse (see Figure 1) so that, following a series of instructions, the participant navigates a virtual 2-D maze on the computer monitor (see Figure 2). RTs are measured from the onset of presentation of instructions to the click on a GUI button, with the choice of button selected by the participant logged online. At the end of the sessions, logged data are saved as a MATLAB data file (mat file). Saved data are analyzed offline using analyzing scripts written in MATLAB.

When the RWT program is executed, a MATLAB figure window $(20 \times 20 \mathrm{~cm})$ initially appears. This window has a grid of $33 \times 33$ virtual cells $(6 \times 6 \mathrm{~mm})$. A GUI pushbutton labeled "Go" (Go button) appears at the centermost cell of the window $([0,0]$ in Cartesian coordinates). If participants click this Go button, a single navigation 
A

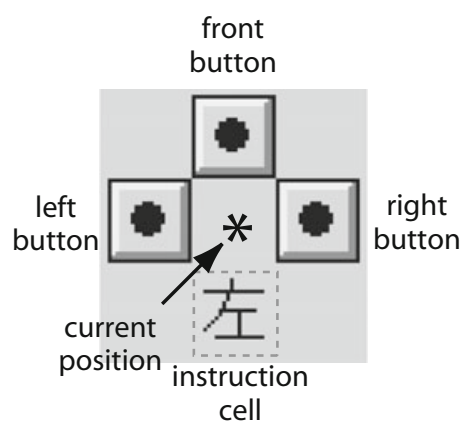

B

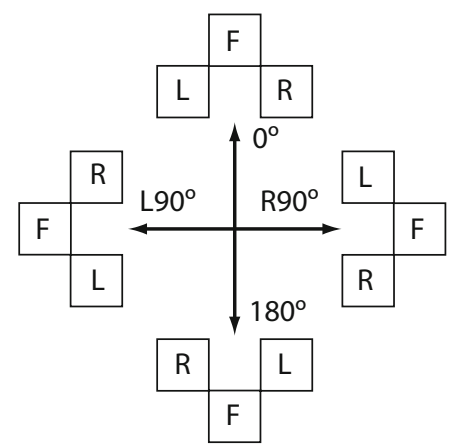

C

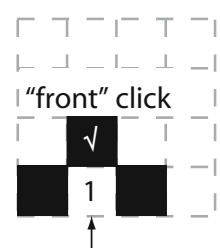

first current

position

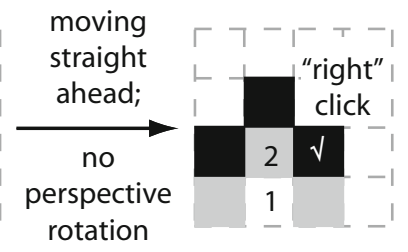

$\left(0^{\circ}\right.$ to $\left.0^{\circ}\right)$

Figure 2. (A) Arrangement of graphical-user-interface buttons and an instruction cell. Left, front, and right buttons and an instruction cell are orthogonally adjacent to the current position (*). (B) Four perspectives in the Random Walker Test (RWT): $0^{\circ}, \mathrm{L90}^{\circ}, \mathrm{RO}^{\circ}$, and $180^{\circ}$. (C) Hypothetical first three steps (front, right, and left) of navigation in the RWT. Black squares indicate positions of the present set of buttons, and gray squares indicate positions of the previous set of buttons. Numbers indicate the trajectory of the current position.

set starts. The position of the cell clicked most recently is designated as the current position. Therefore, when the Go button is clicked, the first current position is at the centermost cell. The first set of three GUI pushbuttons $(6 \times 6 \mathrm{~mm})$ appears in three of four cells $([1,0],[-1,0],[0,1]$, and $[0,-1])$ orthogonally adjacent to the current position. Four orientations are possible for the first set of three GUI buttons, and these four orientations are related to perspectives participants can take. The three GUI buttons are provided in a pyramid shape, with the apex of the pyramid indicating the perspective (Figure 2B). Four perspectives are available: upright $\left(0^{\circ}\right)$, rotated counterclockwise by $90^{\circ}\left(\mathrm{L} 90^{\circ}\right)$, rotated clockwise by $90^{\circ}$ $\left(\mathrm{R} 90^{\circ}\right)$, and upside down $\left(180^{\circ}\right)$. The first perspective in the navigation set is randomly selected with an equal probability of $25 \%$. After a delay of $0.2 \mathrm{sec}$ from the onset of button presentation, a directional instruction appears in the rest of the four cells orthogonally adjacent to the centermost cell (Figures 1 and 2). After the instruction, the participant clicks one of the buttons, after which all the buttons and instructions disappear, the current position moves to the cell in which the button has just been clicked, and a new set of three GUI buttons appears at the three cells surrounding the new current position. The perspective of the newly appeared button set depends on which button of the previous button set was chosen. The left button is designated to turn left, so perspective rotates counterclockwise by $90^{\circ}$ from the previous state; the right button is designated to turn right, so perspective rotates clockwise by $90^{\circ}$; the front button is designated to go straight ahead, so perspective remains the same. The participant repeats spatial judgments after computer-generated instructions until the navigation set ends. A certain number of navigation sets is completed in every session.

In the present experiment, two kinds of instructions were provided: verbal and nonverbal (Figure 1). Verbal instructions were presented as three Japanese kanji (characters) meaning left, right, and front (Figures 1A-1C), pronounced as hidari, migi, and mae, respectively. These characters are very elementary and are taught in the first and second grades of elementary school in Japan. Nonverbal instructions were presented as four graphical arrows (Figures $1 \mathrm{D}-1 \mathrm{~F}$ ) that were orthogonally oriented (upward, downward, leftward, and rightward) and belonged to the same font family as the three Japanese kanji characters. The internal processes of participants for the two instruction categories seem quite different from one another (see the Discussion section), and responses to nonverbal instructions were treated as controls.

Three kinds of instructions and four kinds of perspectives were used in verbal judgments - that is, 12 combinations of judgments and perspectives (e.g., left judgments in $180^{\circ}$ perspective). Instructions were randomly selected with certain probabilities (30\% for front and 35\% for left and right). Incidences of the 12 combinations varied from 30 to 96 , and incidences of front and left-right judgments varied from 194 to 262 and from 488 to 556, respectively, from a total of 750 judgments.

\section{Experimental Sessions}

The participants performed three successive weekly sessions. On Day 1, the participants were fully briefed as to how to perform the RWT, using an instruction demonstration program, and were also taught to complete the test as quickly and accurately as possible. Each session included verbal and nonverbal judgment sets. Single navigation sets had 25 steps, and tests for each judgment type had 11 navigation sets, so 550 judgments were completed in each session. The participants were allowed to take a short break between navigation sets, and most participants completed each session in $<20 \mathrm{~min}$

\section{Data Analysis}

Data from the first navigation set of each session were omitted as trial sets, so 1,500 response samples [ 25 steps $\times 10$ navigation sets $\times 2$ judgment types (verbal and nonverbal) $\times 3$ weekly sessions] per participant were analyzed. One participant performed 
longer sessions, and 1,800 judgments were recorded for him. RTs of false choices were omitted from averaging.

RTs for each individual judgment type showed lognormal-like distributions. We initially averaged logarithms of raw data, then calculated an antilogarithm of the averaged value and used the value as an individual average. Most distributions of individual averages for RTs and error rates (ERs) deviated from normal distributions, and nonparametric methods were employed for statistical analysis. The Wilcoxon signed-ranks test of equality of medians was used for comparison of two paired-sample populations. A Spearman rank correlation coefficient was used for determining correlations between two paired-sample populations.

Most population data were plotted as boxplots, indicating median, lower, and upper quartiles, interquartile range (IQR), and minimum and maximum values. Data points beyond 1.5 times the IQR below the lower quartile or above the upper quartile were treated as outliers in boxplots. The IQR/median ratio was used as a nonparametric, distribution-free equivalent of the coefficient of variation (CV).

\section{RESULTS}

Using the RWT, we evaluated the left-right orientation of 38 right-handed male university students. The statisti- cal properties of the responses varied depending on the combination of judgment types (verbal or nonverbal; left, right, or front) and perspectives $\left(0^{\circ}, \mathrm{L} 90^{\circ}, \mathrm{R} 90^{\circ}\right.$, or $\left.180^{\circ}\right)$. All the participants responded to nonverbal judgments more quickly and steadily. Individual averages of the RTs ranged from 604 to $834 \mathrm{msec}$ (average, $697 \mathrm{msec}$; median, $694 \mathrm{msec}$ ) (see Figure 3A). The average ER for nonverbal judgments was $0.13 \%$ (range, $0 \%-0.67 \%$; median, $0.0667 \%)$, and $50 \%$ of the participants (19/38) made no error in 750 nonverbal judgments (Figure 3B). In the following section, RTs and ERs for nonverbal judgments are treated as controls, and RT and ER differences from nonverbal controls are denoted by $\Delta \mathrm{RT}$ and $\Delta \mathrm{ER}$.

Verbal instructions required longer RTs than were required for nonverbal controls. The average RT for front judgments in all perspectives was $802 \mathrm{msec}$ (range, 685-977 msec; median, $793 \mathrm{msec}$ ), and the average RT for left-right judgments in all perspectives was $951 \mathrm{msec}$ (range, 770-1,214 msec; median, $939 \mathrm{msec}$ ) (Figure 3A). These three data populations for RTs for nonverbal, front, and left-right judgments differed significantly from one
A

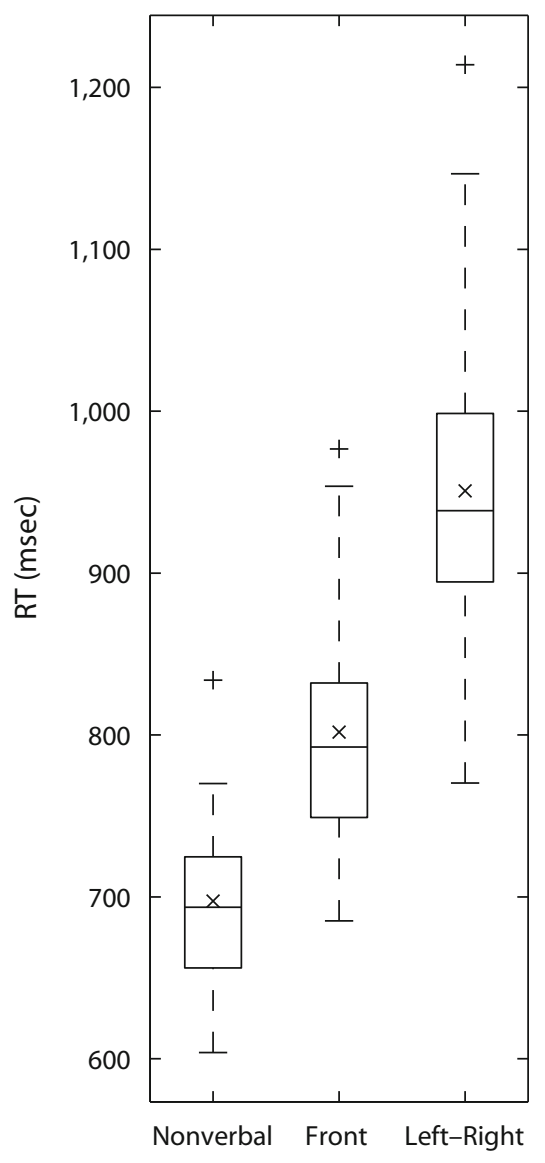

Type of Judgment
B

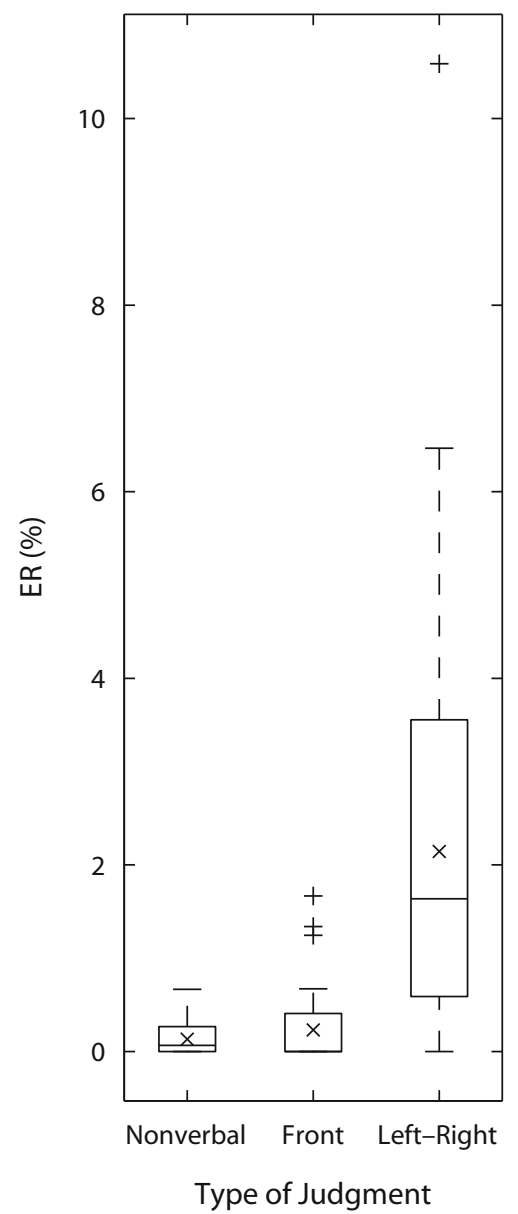

C

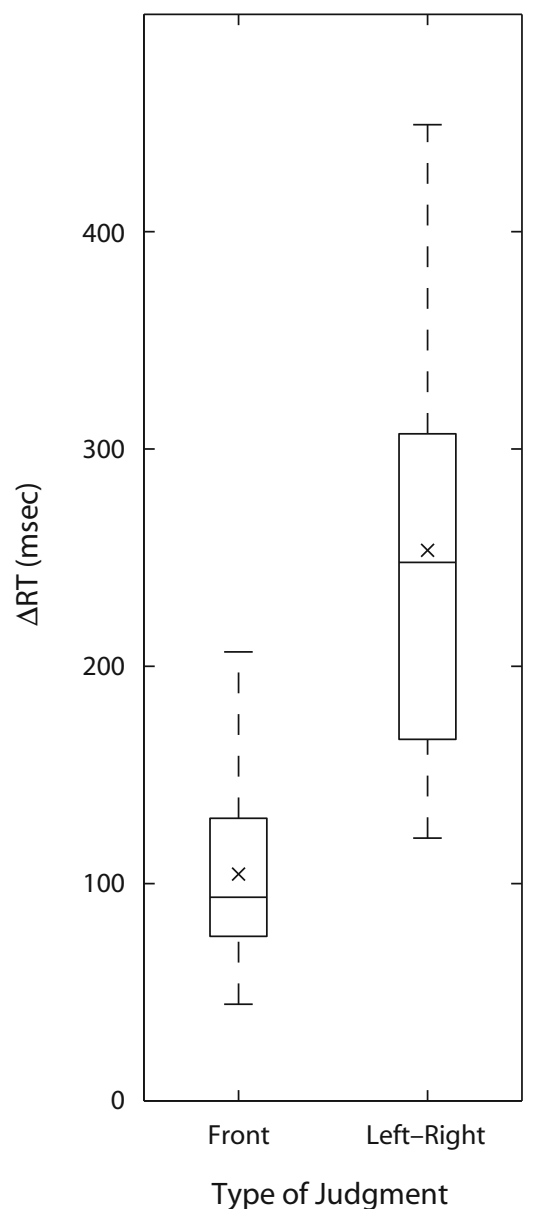

Figure 3. (A) Boxplots of reaction times (RTs) for nonverbal, front, and left-right judgments. See the Method section for an explanation of the boxplots. Outliers are labeled with "+", and arithmetic averages are also plotted with "x" on boxplots. (B) Boxplots of error rates (ERs) for nonverbal, front, and left-right judgments. (C) Boxplots of differences in RTs from nonverbal controls $(\Delta R T s)$ for front and left-right judgments. 
A

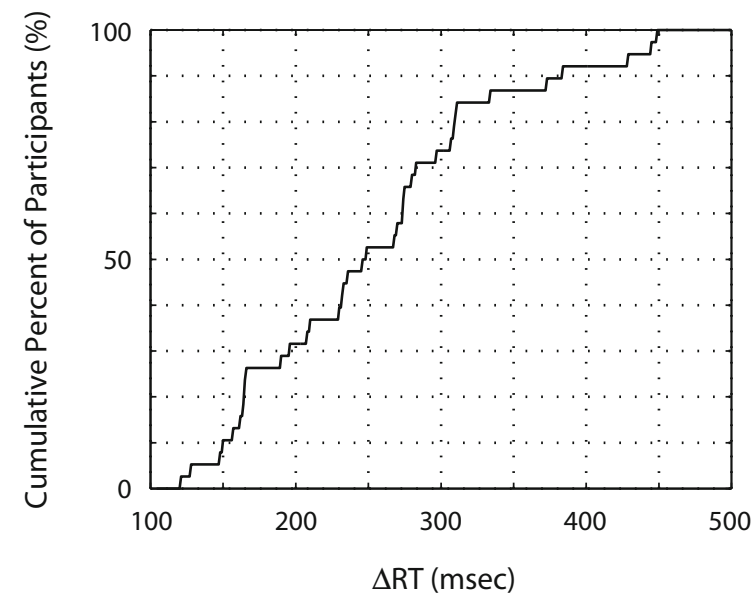

C

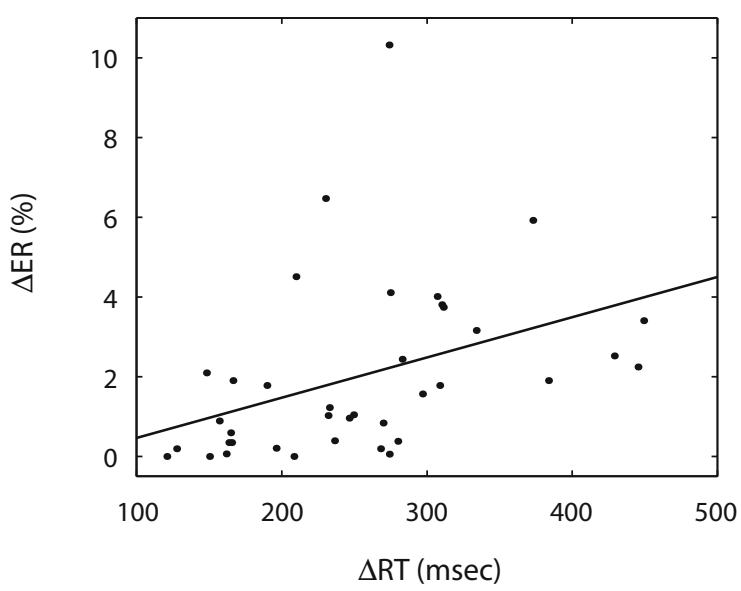

\section{B}

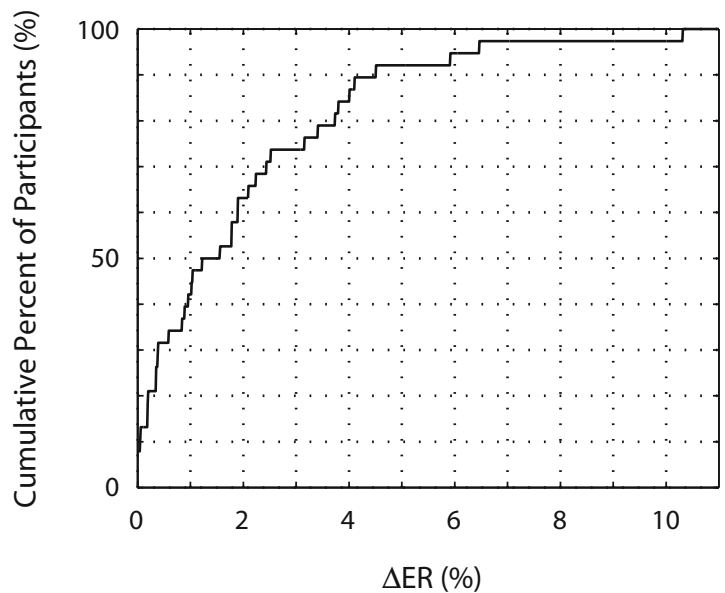

D

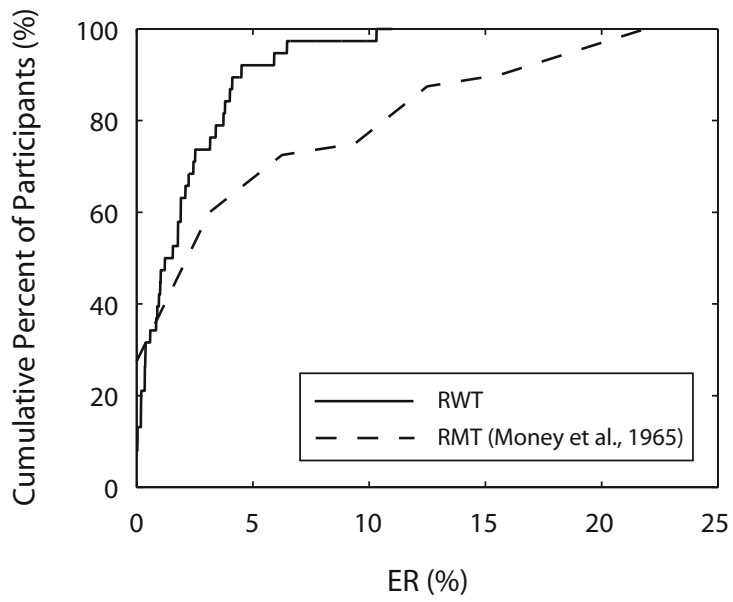

Figure 4. (A) Cumulative distribution function of differences in reaction times from nonverbal controls ( $\Delta R T$ s) for left-right judgments. (B) Cumulative distribution function of differences in error rates from nonverbal controls ( $\Delta E R s)$ for left-right judgments. (C) Relationship between $\Delta \mathrm{RT}$ and $\Delta \mathrm{ER}$ for left-right judgments. Solid line indicates the regression line of data. (D) Cumulative distribution functions of ERs for left-right judgments. Solid line indicates the same data as those shown in panel B. Dotted line indicates control data for young females evaluated by the Road-Map Test (RMT) as cited in Money, Alexander, and Walker (1965). RWT, Random Walk Test.

another (Wilcoxon signed-ranks test, $p<10^{-7}$ ). IQR/ median ratios for nonverbal, front, and left-right judgments were $33.1 \%, 36.8 \%$, and $47.3 \%$, respectively, suggesting a larger interpersonal variation for left-right judgments than for nonverbal and front judgments. Average $\Delta$ RTs were $104 \mathrm{msec}$ (range, 45-207 msec; median, $94 \mathrm{msec}$ ) for front judgments and $253 \mathrm{msec}$ (range, 121$449 \mathrm{msec}$; median, $248 \mathrm{msec}$ ) for left-right judgments (Figure 3C).

ERs for front judgments (mean, $0.23 \%$; range, $0 \%-$ $1.67 \%$; median, $0 \%$ ) did not differ significantly from those for nonverbal judgments (Wilcoxon test, $p=$ .184). ERs for left-right judgments (mean, $2.14 \%$; range, $0 \%-10.59 \%$; median, $1.74 \%$ ) were significantly higher than those for nonverbal and front judgments (16.5 and 9.3 times larger, on average, than those for nonverbal and front instructions, respectively; Wilcoxon test, $p<10^{-6}$ ) (Figure 3B).
Cumulative distribution functions of $\Delta \mathrm{RTs}$ and $\Delta \mathrm{ERs}$ for left-right judgments are shown in Figure 4. The $\Delta$ RTs and $\Delta$ ERs for left-right judgments showed large interpersonal variations. These two values were highly correlated (Spearman rank correlation coefficient $=.585, p<10^{-3}$ ) (Figure 4C).

Perspective rotation affected RTs for left-right judgments (Figure 5). Average $\Delta$ RTs for front judgments were $95,136,122$, and $78 \mathrm{msec}$ for the $0^{\circ}, \mathrm{L} 90^{\circ}, \mathrm{R} 90^{\circ}$, and $180^{\circ}$ perspectives, respectively. Front judgments for the $\mathrm{L} 90^{\circ}$ and $\mathrm{R} 90^{\circ}$ perspectives took 41 and $27 \mathrm{msec}$ more, respectively, than did those for the $0^{\circ}$ perspective, and those for the $180^{\circ}$ perspective took $17 \mathrm{msec}$ less than did those for the $0^{\circ}$ perspective. Average $\Delta$ RTs for left-right judgments were $192,227,221$, and $400 \mathrm{msec}$ for the $0^{\circ}, \mathrm{L} 90^{\circ}, \mathrm{R} 90^{\circ}$, and $180^{\circ}$ perspectives, respectively. The effects of perspective rotation on front and left-right judgments thus differed significantly, particularly for the $180^{\circ}$ perspective. 


\section{A Front Judgments}

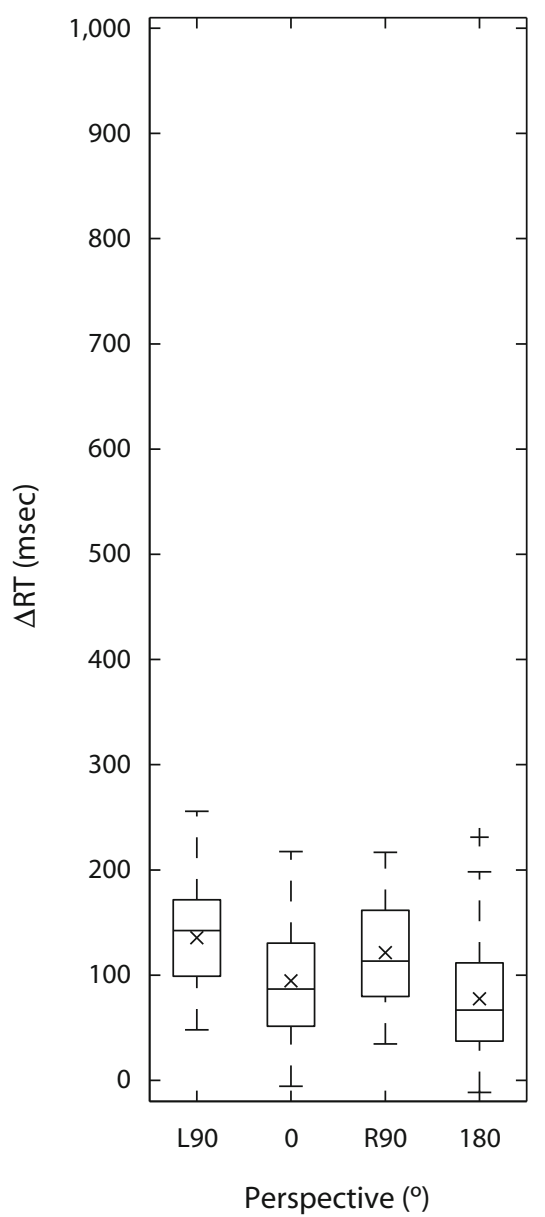

B Left Judgments

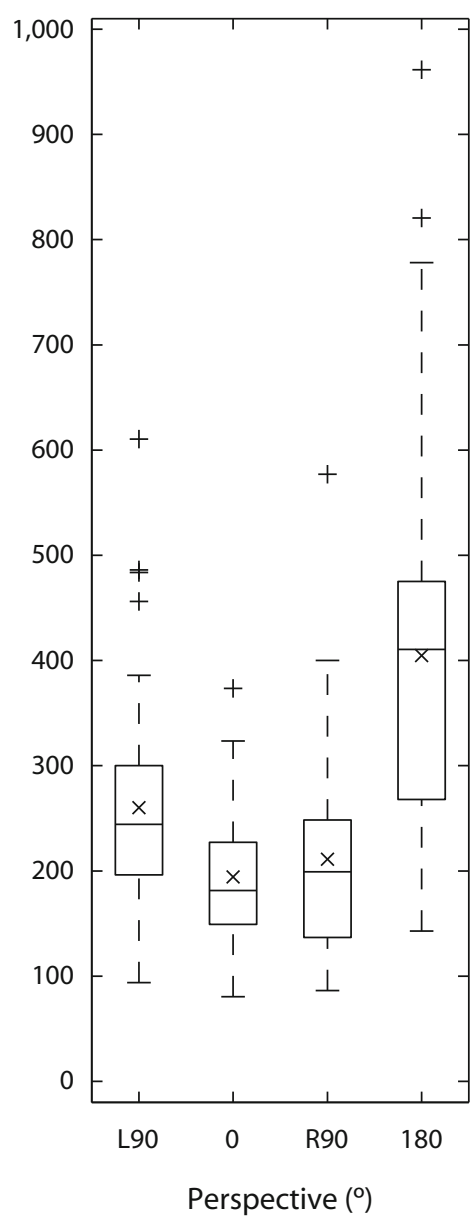

C Right Judgments

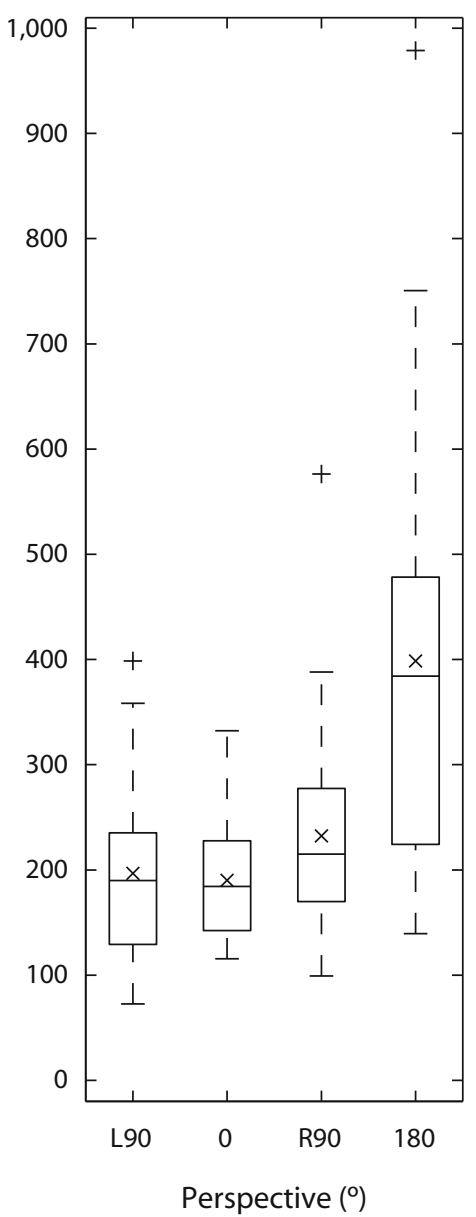

Figure 5. Boxplots of differences in reaction times from nonverbal controls ( $\Delta$ RTs) for front (A), left (B), and right (C) judgments for the $\mathrm{LSO}^{\circ}, \mathrm{O}^{\circ}, \mathrm{R}^{\circ}$, and $180^{\circ}$ perspectives.

Left-right judgments for the $\mathrm{L} 90^{\circ}, \mathrm{R} 90^{\circ}$, and $180^{\circ}$ perspectives took 35, 29, and 208 msec more, respectively, than did those for the $0^{\circ}$ perspective. The effects of perspective rotation on RTs were dissociated for left and right judgments (Figures 5B and 5C). For left judgments, RTs were significantly longer for the $\mathrm{L} 90^{\circ}$ and $180^{\circ}$ perspectives than were those for the $0^{\circ}$ perspective, but not for the $\mathrm{R} 90^{\circ}$ perspective (Wilcoxon test, $p<10^{-5}$ for the $\mathrm{L} 90^{\circ}$ perspective, $p<10^{-7}$ for the $180^{\circ}$ perspective, $p=.104$ for the $\mathrm{R} 90^{\circ}$ perspective) (Figure 5B). For right judgments, RTs were significantly longer for the R $90^{\circ}$ and $180^{\circ}$ perspectives than for the $0^{\circ}$ perspective, but not for the $\mathrm{L} 90^{\circ}$ perspective (Wilcoxon test, $p<10^{-3}$ for the $\mathrm{R} 90^{\circ}$ perspective, $p<10^{-6}$ for the $180^{\circ}$ perspective, $p=$ .252 for the $\mathrm{L} 90^{\circ}$ perspective) (Figure $5 \mathrm{C}$ ). RTs for left and right judgments were very similar for the $0^{\circ}$ and $180^{\circ}$ perspectives (Wilcoxon test, $p=.353$ for the $0^{\circ}$ perspective, $p=.276$ for the $180^{\circ}$ perspective), but those for the $\mathrm{L} 90^{\circ}$ and $\mathrm{R} 90^{\circ}$ perspectives were significantly different (Wilcoxon test, $p<10^{-5}$ for $\mathrm{L} 90^{\circ}, p=.0449$ for $\mathrm{R} 90^{\circ}$ ). That is, for the $\mathrm{L} 90^{\circ}$ perspective, the average RT for left judgments was longer than that for right judgments by
$64 \mathrm{msec}$; for the $\mathrm{R} 90^{\circ}$ perspective, the average RT for right judgments was longer than that for left judgments by $21 \mathrm{msec}$.

Perspective rotation also affected ERs for left-right judgments (see Figure 6). ERs for front judgments were unaffected by perspective rotation (Figure 6A). Average ERs for left-right judgments for the $\mathrm{L} 90^{\circ}, \mathrm{R} 90^{\circ}$, and $180^{\circ}$ perspectives were approximately $2.3,2.0$, and 7.2 times higher, respectively, than that for the $0^{\circ}$ perspective. The average ER for left judgments for the $180^{\circ}$ perspective was 1.9 times higher than that for right judgments for the $180^{\circ}$ perspective (Figures 6B and 6C), but ERs were not significantly different between left and right judgments for the $0^{\circ}, \mathrm{L} 90^{\circ}$, and $\mathrm{R} 90^{\circ}$ perspectives. The total error number for left-right judgments for all 38 participants was 412 . Incidences were corrected by numbers of each type of judgments in the RWT. Errors for left judgments for the $180^{\circ}$ perspective comprised $38 \%$ of the total errors, almost twice the number of errors for right judgments for the $180^{\circ}$ perspective.

Cumulative distribution functions of RT and ER differences for left-right judgments between the $0^{\circ}$ and 
A Front Judgments

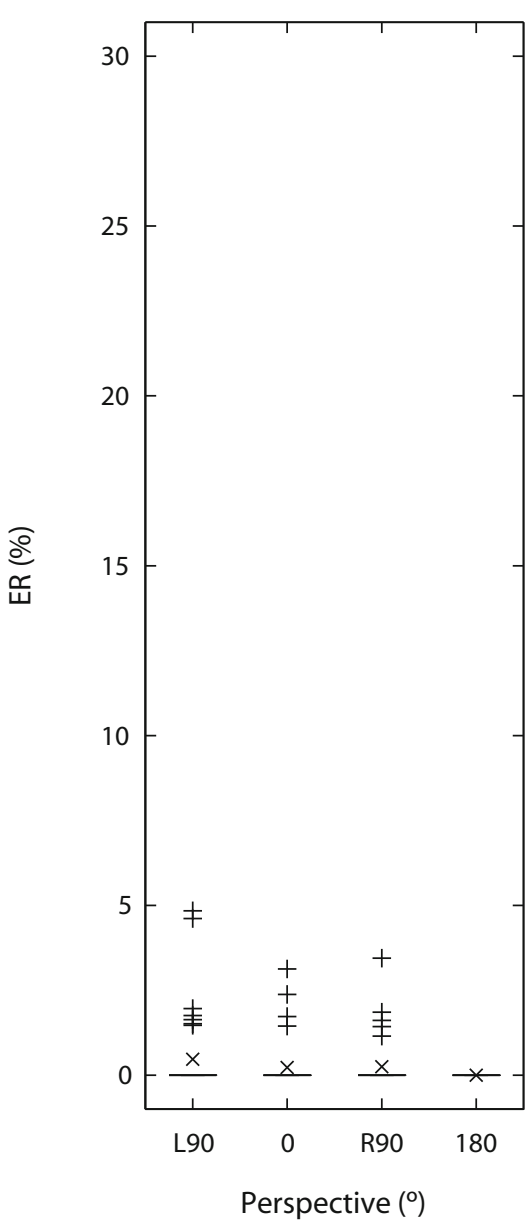

B Left Judgments

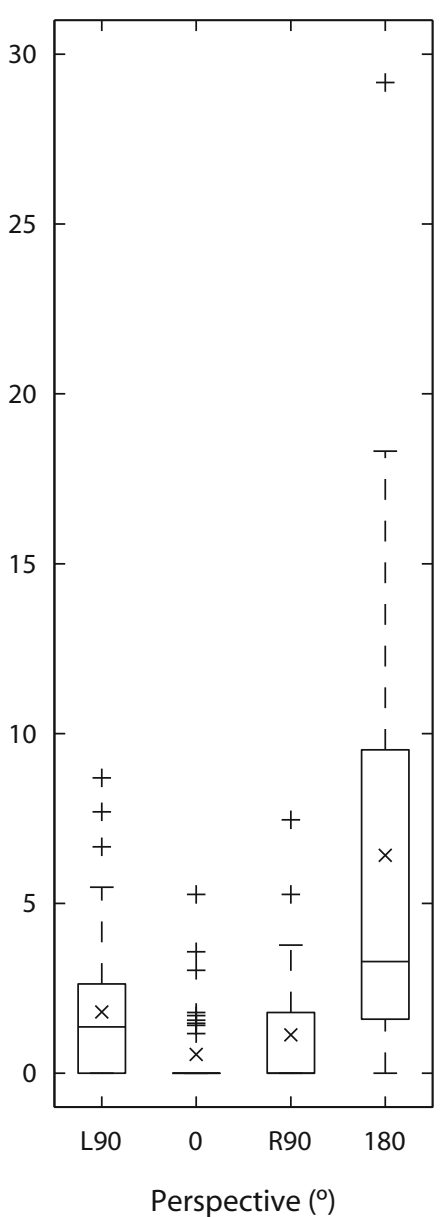

C Right Judgments

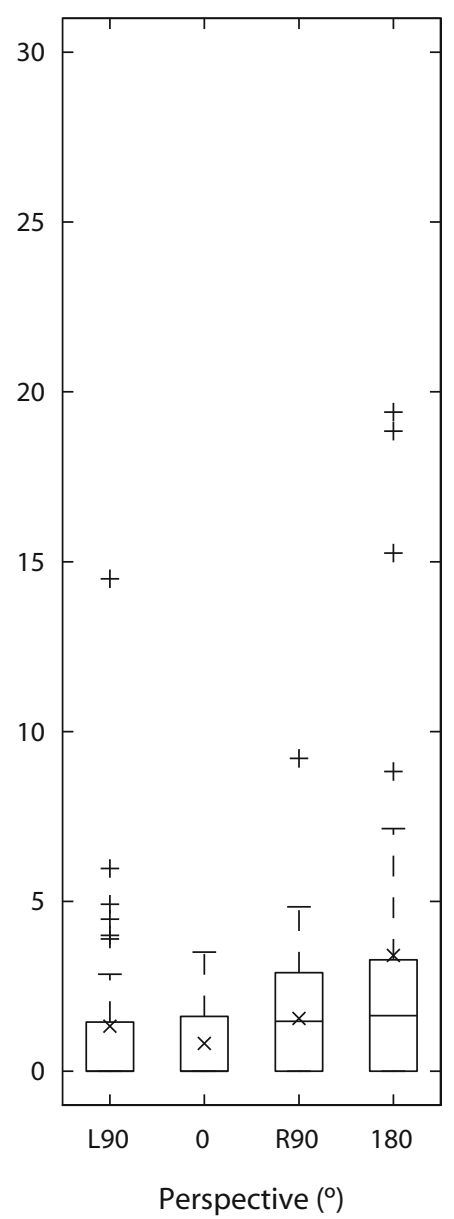

Figure 6. Boxplots of error rates for front (A), left (B), and right (C) judgments for the $\mathrm{Lg0}^{\circ}, 0^{\circ}, \mathrm{RO}^{\circ}$, and $180^{\circ}$ perspectives. All the boxes in panel $A$ and the box for the $0^{\circ}$ perspective in panel $B$ are collapsed, because all medians and lower and upper quartiles are 0 or very close to 0 .

$180^{\circ}$ perspectives are shown in Figure 7 . These two values showed large interpersonal variations and a moderate correlation with one another (Spearman rank correlation coefficient $=.476, p=.0025)$ (Figure 7C).

CVs were calculated for RT data populations for each judgment category for each participant. Most RT data populations showed log-normal-like distributions, so CVs were calculated for logarithms of RTs. Distributions of individual CVs are shown in Figure 8. For left-right judgments, perspective rotations increased CVs of RTs, so intrapersonal variations of RTs were also increased with perspective rotation (Wilcoxon test, $p<10^{-3}$ ).

Observations of individuals in three successive weekly sessions revealed improved RTs in all conditions, but improvement of left-right mapping and perspective rotation took different time courses. The $\Delta$ RTs of left-right judgments for the $180^{\circ}$ perspective improved from the first to the second session but did not change significantly from the second to the third session (Wilcoxon test, $p<$ $10^{-3}$ between the first and second sessions, $p=.0695$ between the second and third sessions) (Figure 9C). Av- erage $\Delta \mathrm{RT}$ s for front judgments for all perspectives and left-right judgments for the $0^{\circ}$ perspective decreased slightly from the first to the third session (Figures 9A and 9B). Accuracy of left-right judgments for the $180^{\circ}$ perspective showed some improvement from the first to the second session (Wilcoxon test, $p=.0191$; range, $0 \%-43.14 \%$ to $0 \%-18.42 \%$; median, $4.46 \%-2.47 \%$; mean, $6.69 \%-4.35 \%$ ), but relatively high ERs (range, 0\%-18.60\%; median, $2.12 \%$; mean, $3.75 \%$ ) were still seen even in the third session (Figures 7D and 10C). No significant improvements in ERs was observed in the front judgments for any perspectives and the left-right judgments for the $0^{\circ}$ perspective during the three sessions (Figures 10A and 10B).

\section{DISCUSSION}

In the RWT, the participants view the 2-D maze as a survey map from a bird's-eye perspective, although the maze is vertically presented on the computer monitor. The participants thus equate the vertical plane on the 
A

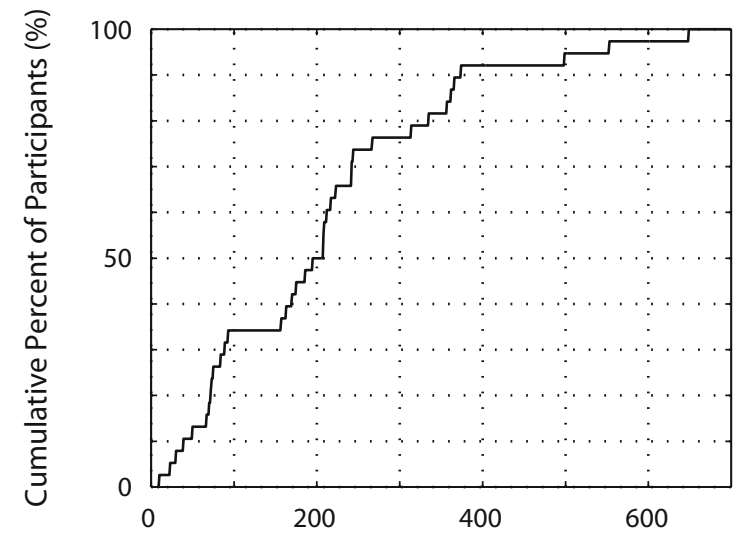

$\Delta$ RT Between $0^{\circ}$ and $180^{\circ}$ Perspectives (msec)

\section{C}

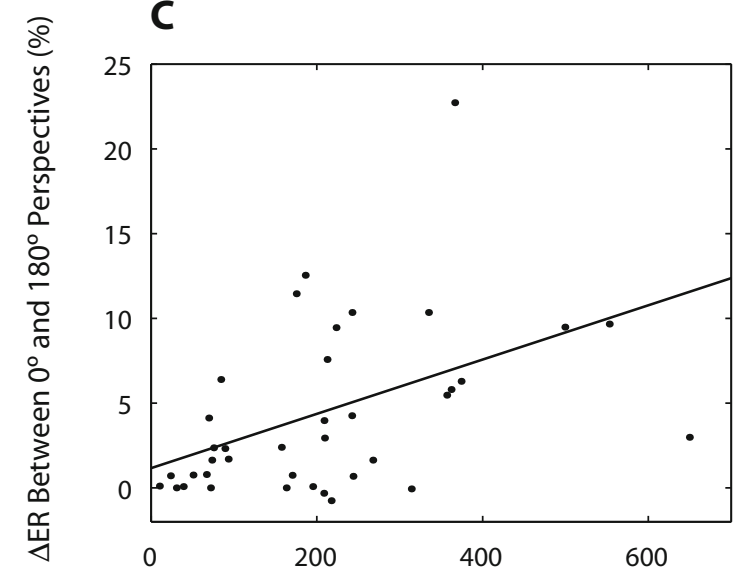

$\Delta \mathrm{RT}$ Between $0^{\circ}$ and $180^{\circ}$ Perspectives (msec)
B

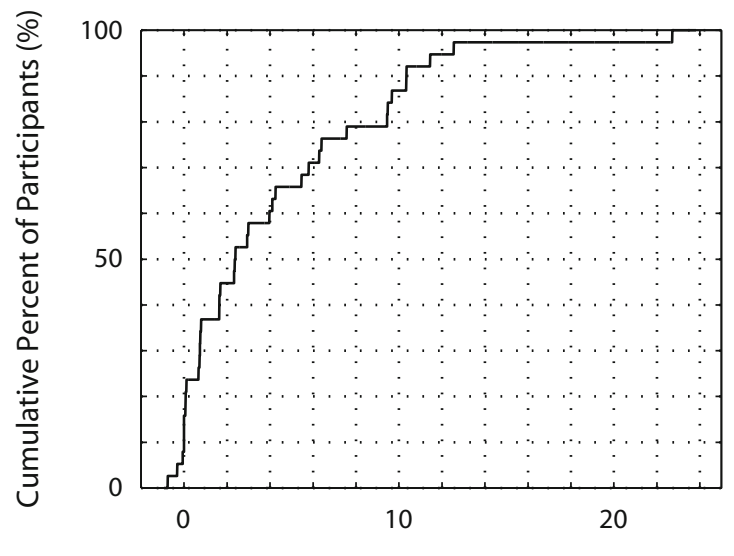

$\Delta$ ER Between $0^{\circ}$ and $180^{\circ}$ Perspectives (\%)

D

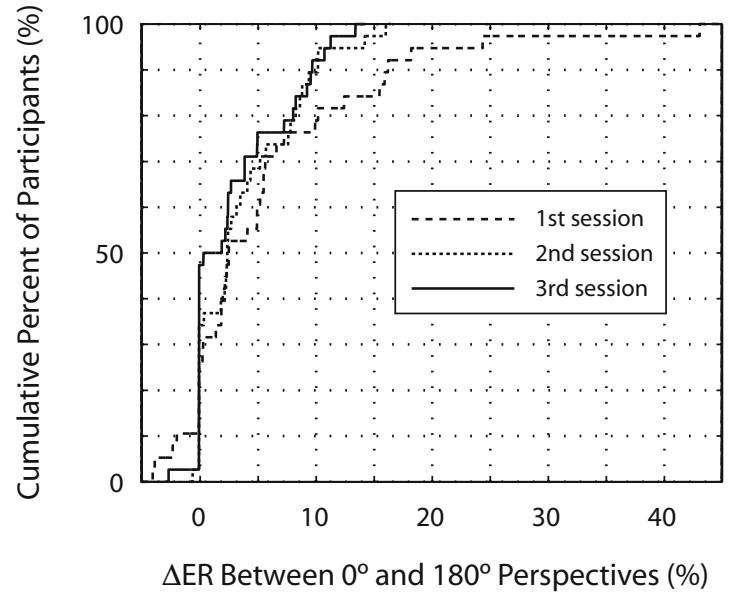

Figure 7. (A) Cumulative distribution function of differences in reaction times from nonverbal controls ( $\Delta R T s)$ between the $0^{\circ}$ and $180^{\circ}$ perspectives. (B) Cumulative distribution function of differences in error rates from nonverbal controls ( $\triangle E$ ERs) between the $0^{\circ}$ and $180^{\circ}$ perspectives. (C) Relationship between $\Delta R T$ and $\Delta E R$ between the $0^{\circ}$ and $180^{\circ}$ perspectives. Solid line indicates the regression line of data. (D) Cumulative distribution functions of $\Delta \mathrm{ER}$ between the $0^{\circ}$ and $180^{\circ}$ perspectives in the first, second, and third weekly sessions.

computer monitor with the ground (horizontal) plane, and verbal judgments of left-right in the RWT require egocentric rotation of perspective on the ground plane, as was noted previously (Shepard \& Hurwitz, 1984). Conversely, nonverbal judgments instructed with graphical arrows may be performed in the intrinsic frame of reference, in which intrinsic (internal) topographical relationships among objects (the three GUI buttons in the case of the RWT) within the frame are exclusively essential. Nonverbal judgments in the RWT are therefore free from the constraint of perspective. The present study confirmed that left-right orientation requires two independent mental components: verbal-spatial mapping of left-right to a particular direction of the egocentric frame of reference and egocentric perspective rotation. Similarly, the vast majority of participants are known to adopt a strategy of egocentric perspective rotation (move self) for executing the RMT (Schultz, 1991). This distinction suggests that two independent neural systems may be involved in leftright orientation.

Verbal-spatial mappings are thought to be implemented as an interface between the language system and the system for integration and transformation of multisensory spatial coordinates in the brain. The language system is predominantly implemented in the temporal cortex and surrounding areas in the left hemisphere (Price, 2000), whereas the system for integration and transformation of spatial coordinates is implemented mainly in the posterior parietal cortex in both hemispheres (Andersen \& Buneo, 2002). One strong candidate for cortical areas interfacing verbal-spatial mapping of left-right is the angular gyrus of the left hemisphere (Benton \& Sivan, 1993; Kemmerer, 2006), which is located at the topographical junction between the language system and the spatial coordinate system. Localized damage to the left angular gyrus causes Gerstmann's syndrome, with major symptoms including 


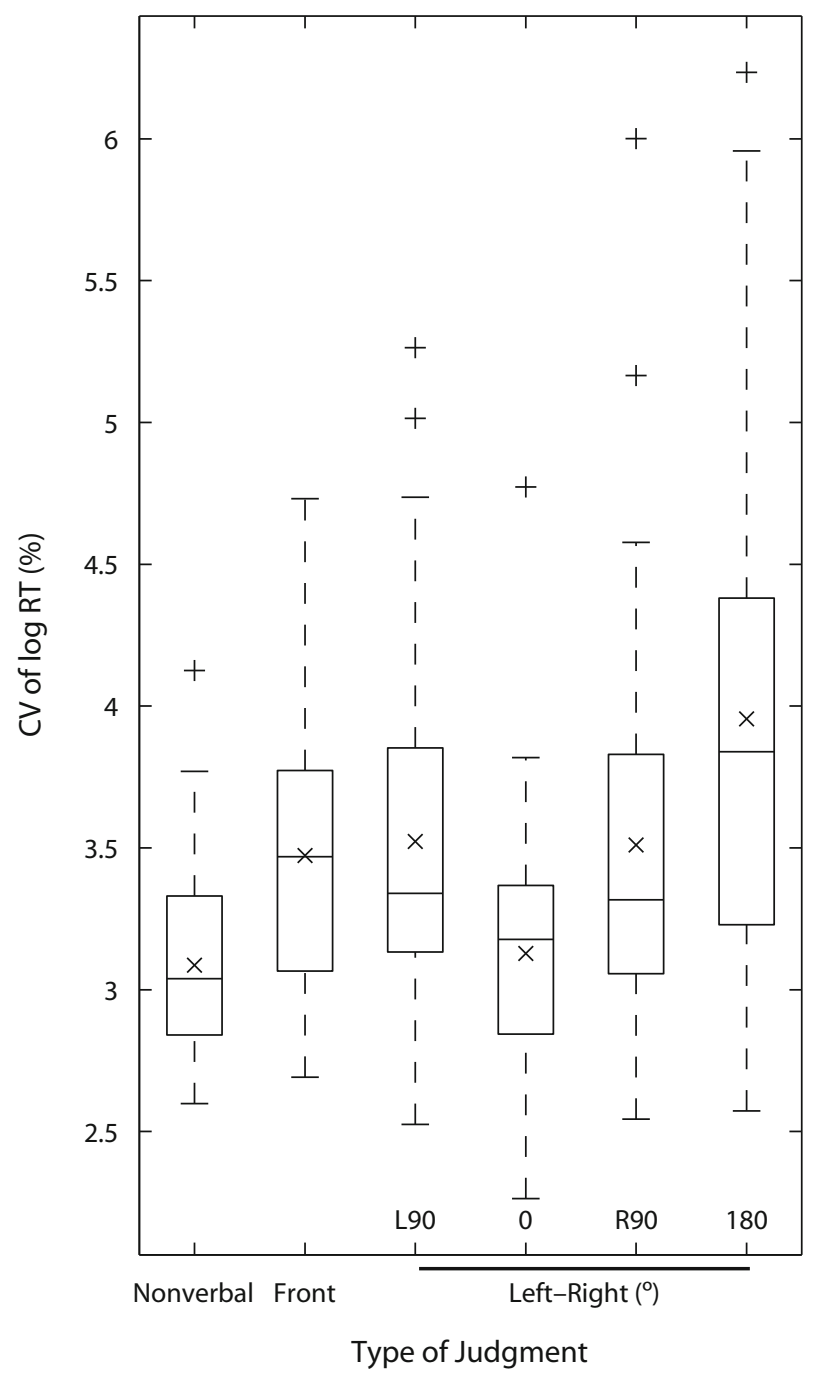

Figure 8. Boxplots of coefficients of variation (CVs) of logarithms (log) of reaction times (RTs) of participants for each judgment type.

left-right disorientation (Mayer et al., 1999). Focal electrical stimulation of the left angular gyrus elicits left-right disorientation (Morris, Lüders, Lesser, Dinner, \& Hahn, 1984). Functional imaging studies of normal participants performing RWT-type tasks would be helpful for examining whether the left angular gyrus is responsible for verbal-spatial mapping of left-right.

Mental rotation is the act of imagining something turning around (Corballis, 1997; Shepard \& Cooper, 1982). Although perspective transformation (or visual perspective-taking) and object-based mental rotation were not clearly distinguished in earlier studies, recent studies have clarified clear dissociations between these two kinds of transformations of visuospatial mental images (Hegarty \& Waller, 2004; Parsons, 1987; Zacks \& Michelon, 2005; Zacks, Vettel, \& Michelon, 2003). Neural systems involving these two mental processes may also be dissociated (see Parsons, 2003; Zacks \& Michelon, 2005), but neuroimaging studies have not yet narrowed down candidates for the cortical regions involved in perspective transformation (Creem-Regehr, Neil, \& Yeh, 2007; Zacks $\&$ Michelon, 2005; Zaehle et al., 2007).

Michelon and Zacks (2006) carried out psychological experiments of visual perspective-taking (Experiments 2 and 3 in their study). The 3-D experimental design seems quite different from the 2-D design of the RWT, but the results for the effects of perspective rotation on RTs for leftright judgments closely resemble the present results. The authors asked participants to report whether an object on a table was to the left or the right of an avatar who confronts the table, changing angular disparity between participants and the avatar. In that study, rotations of perspective by $90^{\circ}$ and $180^{\circ}$ took $40-50$ and $200-250 \mathrm{msec}$ more, very close to the values obtained with the RWT. The experiments by Michelon and Zacks and the RWT may evaluate the same kind of mental process. 
A

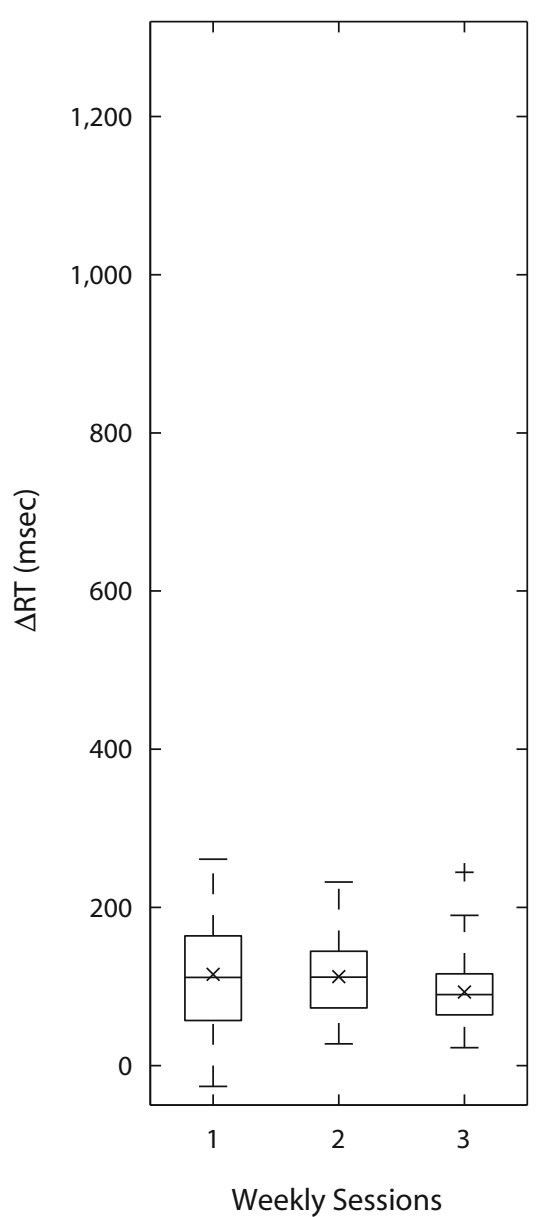

B Left-Right Judgments $\left(0^{\circ}\right)$

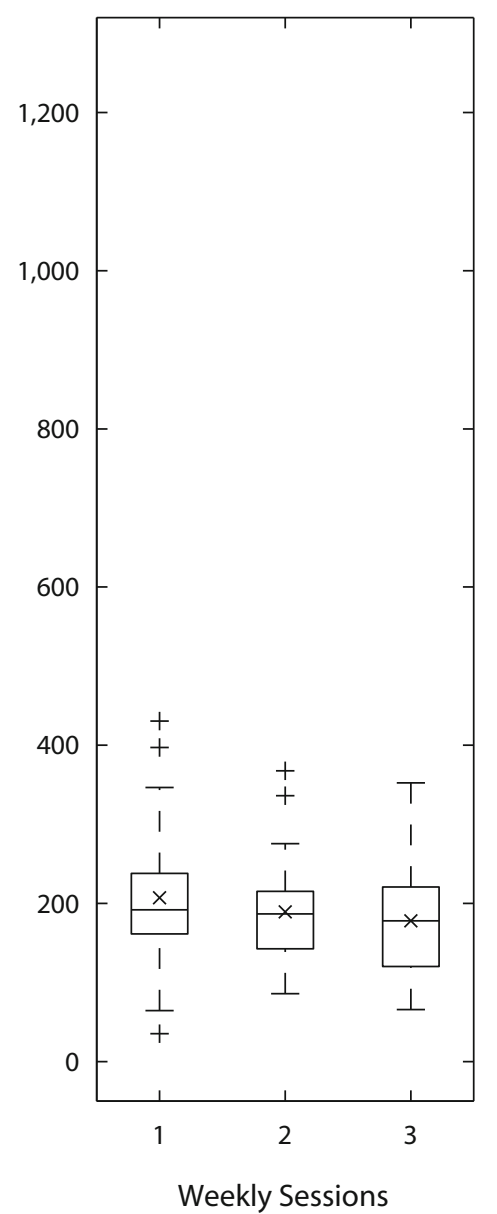

C Left-Right Judgments $\left(180^{\circ}\right)$

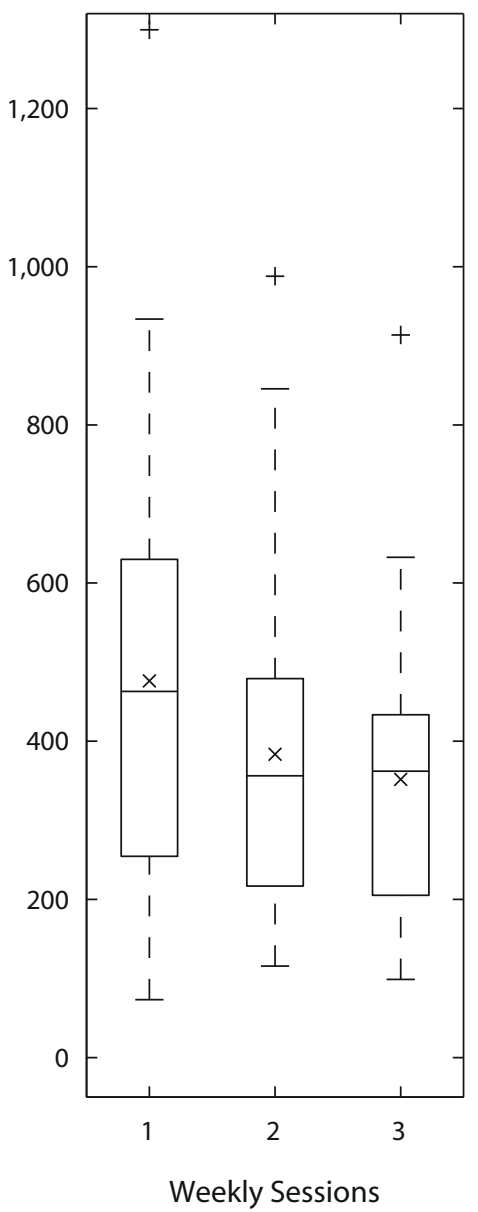

Figure 9. Boxplots of differences in reaction times from nonverbal controls ( $\Delta R T s)$ for the front judgments (A) and left-right judgments for the $0^{\circ}(\mathrm{B})$ and $180^{\circ}(\mathrm{C})$ perspectives in the first, second, and third weekly sessions.

Our study showed that egocentric perspective rotation is an unreliable mental process with large intra- and interpersonal variations. More than one third of participants exhibited ERs $>5 \%$, and $>10 \%$ of participants exhibited ERs $>10 \%$ in left-right judgments for the $180^{\circ}$ perspective. Only 3 participants (7.9\%) performed $488-556$ left-right judgments for all perspectives without an error. Those ERs are quite high, as compared with ERs for nonverbal and front judgments. The same population showed ERs $<0.67 \%$ and $<1.67 \%$ for nonverbal and front judgments, and 19 and 25 participants $(50.0 \%$ and $65.8 \%$, respectively) made 750 nonverbal and 194-262 front judgments, respectively, for all perspectives without error. The high incidence of erroneous judgments in egocentric perspective rotations could be one of many causes of "human error" that may potentially trigger various kinds of accidents. Potential applications of the RWT as a training aid for left-right orientation should be investigated.

This study also suggests asymmetry of perspective rotation for left and right judgments. For $\mathrm{L} 90^{\circ}$ and $\mathrm{R} 90^{\circ}$ perspectives, RTs for left and right judgments are dis- sociated. That is, for right judgments, counterclockwise rotation (from the $0^{\circ}$ to the $\mathrm{L} 90^{\circ}$ perspective) is faster than clockwise rotation (from the $0^{\circ}$ to the $\mathrm{R} 90^{\circ}$ perspective), and vice versa for left judgments. Furthermore, ERs for left judgments are much higher than those for right judgments for the $180^{\circ}$ perspective. These asymmetrical properties are found in right-handed participants. For non-right-handed participants, the properties of the dissociation of left and right judgments differ from those for right-handers (unpublished observation). The relationship between perspective rotation and handedness warrants further study.

The RWT has been developed as a quantitative alternative to the RMT. The RMT and RWT share common basic concepts but differ in some aspects. The high statistical confidence of the data obtained using the RWT should be emphasized, because of the large sampling capacity (at least a few hundred), as compared with only 32 judgment samples for single participants in the RMT (although the RMT offers clear superiority as a simple, quick clinical assessment). A comparison of cumulative 
A

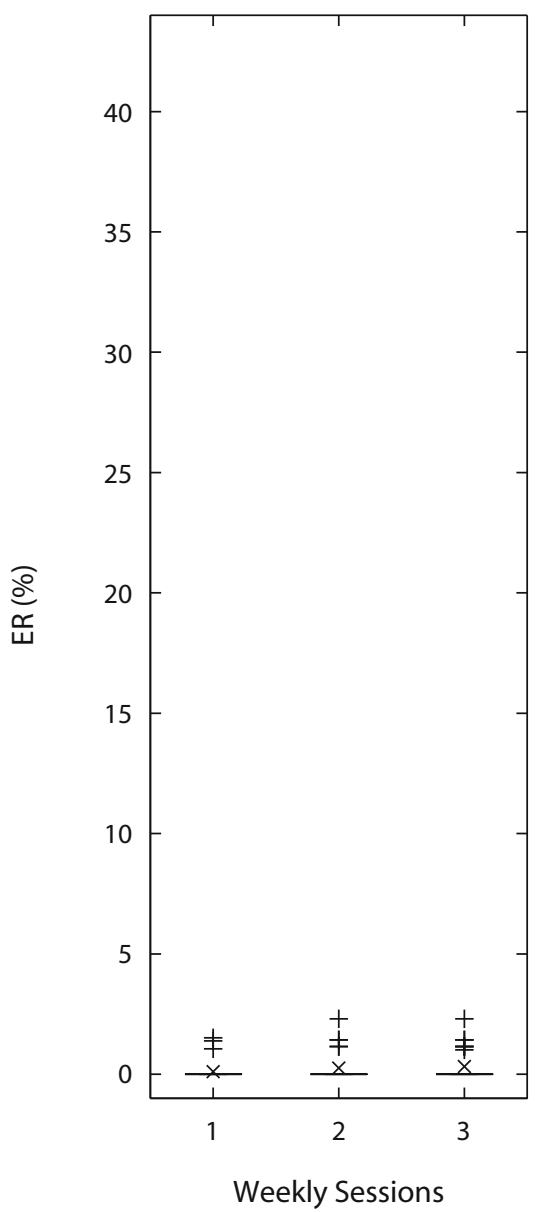

B Left-Right Judgments $\left(0^{\circ}\right)$

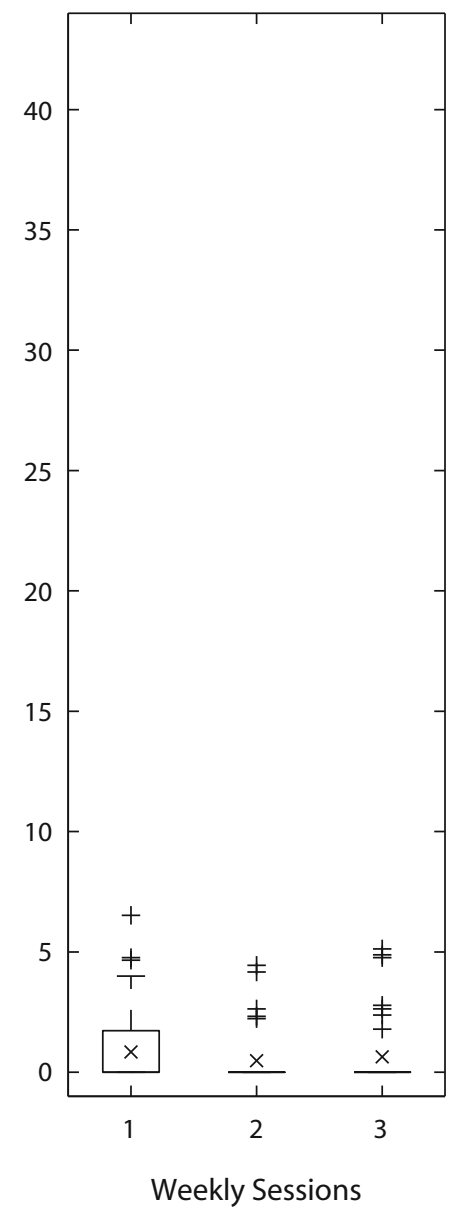

C Left-Right Judgments $\left(180^{\circ}\right)$

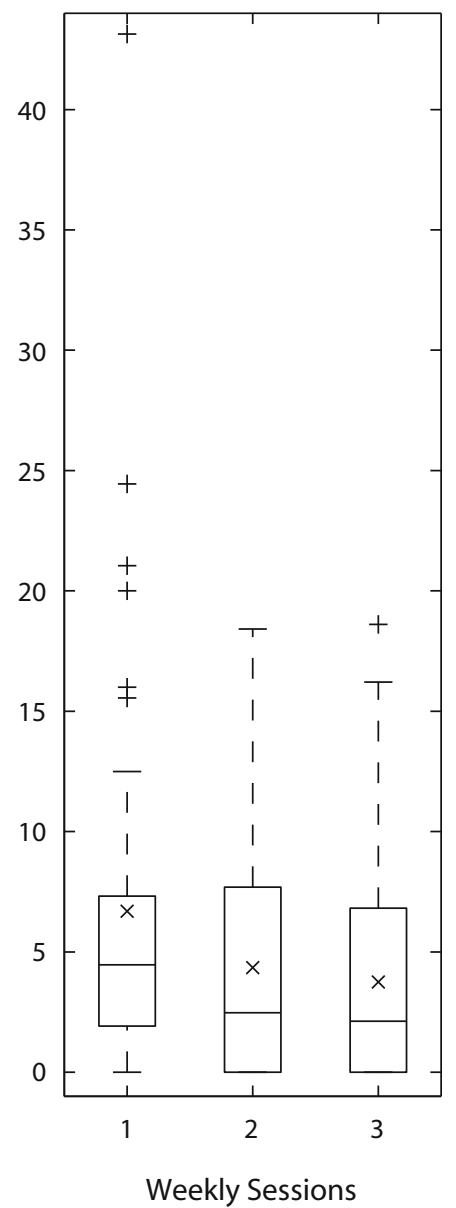

Figure 10. Boxplots of error rates (ERs) for front judgments (A) and left-right judgments for the $0^{\circ}(B)$ and $180^{\circ}(C)$ perspectives in the first, second, and third weekly sessions. Boxes in panels $A$ and $B$ are collapsed, because all medians and lower and upper quartiles are 0 or very close to 0 .

distribution functions for left-right judgments for the RWT and RMT is shown in Figure 4D. Higher ERs in the RMT may reflect possible inexperience in performance, caused by the small number of total judgments. Directions of information transformation between verbal and spatial domains are opposite in the two tests. In the RMT, transformation is made from a spatial domain to a verbal domain (first a visual observation of a spatial turn, then a verbal left-right judgment). Conversely, transformation is made from a verbal domain to a spatial domain in the RWT (first a verbal left-right instruction, then a spatial judgment). Two other differences are apparent regarding the manner of turning in the two tests: (1) All turns are orthogonal in the RWT, but 12 of 32 turns $(37.5 \%)$ are not orthogonal in the RMT, and (2) turns are made at every intersection in the RMT but are not made at some intersections in the RWT.

All the participants were Japanese university students and were easily able to read and respond to instructions in kanji characters denoting left, right, and front. As a trial, we replaced kanji characters with English letters ( $\mathrm{L}$ for left, $\mathrm{R}$ for right, $\mathrm{F}$ for front) and easily made preliminary evaluations of non-Japanese participants. The RWT is thus internationally adjustable, by simple replacement of fonts and text in the program codes. Even participants unfamiliar with a computer mouse may be evaluated using the RWT if a touch screen monitor is equipped. Numbers and dimensions in the RWT are also easily modifiable. Enlargement of the buttons and fonts of the instructions and related modifications would make the RWT more usable for clinical and/or diagnostic purposes. We are planning to publicize MATLAB codes, a compiled program, or an online program of the RWT on the Internet for further external evaluation of the RWT.

\section{AUTHOR NOTE}

Correspondence concerning this article should be addressed to H. Uchiyama, Department of Informatics and Biomedical Engineering, Faculty of Engineering, Kagoshima University, Korimoto 1-21-40, Kagoshima 890-0065, Japan (e-mail: uchiyama@ibe.kagoshima-u.ac.jp). 


\section{REFERENCES}

Andersen, R. A., \& Buneo, C. A. (2002). Intentional maps in posterior parietal cortex. Annual Review of Neuroscience, 25, 189-220.

Benton, A., \& Sivan, A. B. (1993). Disturbances of the body schema. In K. M. Heilman \& E. Valenstein (Eds.), Clinical neuropsychology (3rd ed., pp. 123-140). New York: Oxford University Press.

Bloom, P., Peterson, M. A., Nadel, L., \& Garrett, M. F. (1996). Language and space. Cambridge, MA: MIT Press.

Chatterjee, A. (2001). Language and space: Some interactions. Trends in Cognitive Sciences, 5, 55-61.

Corballis, M. C. (1997). Mental rotation and the right hemisphere. Brain \& Language, 57, 100-121.

Creem-Regehr, S. H., Neil, J. A., \& Yeh, H. J. (2007). Neural correlates of two imagined egocentric transformations. Neurolmage, 35, 916-927.

Dellatolas, G., Viguier, D., Deloche, G., \& De Agostini, M. (1998). Right-left orientation and significance of systematic reversal in children. Cortex, 34, 659-676.

Gold, M., Adair, J. C., Jacobs, D. H., \& Heilman, K. M. (1995). Right-left confusion in Gerstmann's syndrome: A model of body centered spatial orientation. Cortex, 31, 267-283.

Hatta, T., \& Nakatsuka, Z. (1976). Note on hand preference of Japanese people. Perceptual \& Motor Skills, 42, 530.

Haun, D. B. M., Call, J., Janzen, G., \& Levinson, S. C. (2006). Evolutionary psychology of spatial representations in the hominidae. Current Biology, 16, 1736-1740.

Haun, D. B. M., Rapold, C. J., Call, J., Janzen, G., \& Levinson, S. C. (2006). Cognitive cladistics and cultural override in Hominid spatial cognition. Proceedings of the National Academy of Sciences, 103, 17568-17573.

Hegarty, M., \& Waller, D. (2004). A dissociation between mental rotation and perspective-taking spatial abilities. Intelligence, 32, 175-191.

JAGER, G., \& Postma, A. (2003). On the hemispheric specialization for categorical and coordinate spatial relations: A review of the current evidence. Neuropsychologia, 41, 504-515.

KEMmerer, D. (2006). The semantics of space: Integrating linguistic typology and cognitive neuroscience. Neuropsychologia, 44, 1607-1621.

KITA, S. (2006). A grammar of space in Japanese. In S. C. Levinson \& D. Wilkins (Eds.), Grammars of space: Explorations in cognitive diversity (pp. 437-474). Cambridge: Cambridge University Press.

KosSLYN, S. (1987). Seeing and imagining in the cerebral hemispheres: A computational approach. Psychological Review, 94, 148-175.

Laeng, B., Chabris, C. F., \& Kosslyn, S. M. (2003). Asymmetries in encoding spatial relations. In K. Hugdahl \& R. J. Davidson (Eds.), The asymmetrical brain (pp. 303-339). Cambridge, MA: MIT Press.

LAENG, B., \& Peters, M. (1995). Cerebral lateralization for the processing of spatial coordinates and categories in left- and right-handers. Neuropsychologia, 33, 421-439.

LeVInson, S. C., \& WiLKINS, D. (2006). Grammars of space: Explorations in cognitive diversity. Cambridge: Cambridge University Press.

Majid, A., Bowerman, M., Kita, S., Haun, D. B. M., \& Levinson,
S. C. (2004). Can language restructure cognition? The case for space. Trends in Cognitive Sciences, 8, 108-114

Mayer, E., Martory, M. D., Pegna, A. J., Landis, T., Delavelle, J., \& ANNONI, J. M. (1999). A pure case of Gerstmann syndrome with a subangular lesion. Brain, 122, 1107-1120.

Michelon, P., \& ZaCKs, J. M. (2006). Two kinds of visual perspective taking. Perception \& Psychophysics, 68, 327-337.

Money, J., Alexander, D., \& Walker, H. T. (1965). A standardized road-map test of direction sense: Manual. Baltimore: Johns Hopkins Press.

Morris, H., Lüders, H., Lesser, R., Dinner, D., \& Hahn, J. (1984). Transient neuropsychological abnormalities (including Gerstmann's syndrome) during cortical stimulation. Neurology, 34, 877-883.

Nijhuis-van der Sanden, M. W. G., Eling, P., \& Otten, B. J. (2003). A review of neuropsychological and motor studies in Turner syndrome. Neuroscience \& Biobehavioral Reviews, 27, 329-338.

PARSONS, L. (1987). Imagined spatial transformation of one's body. Journal of Experimental Psychology: General, 116, 172-191.

PARSONS, L. (2003). Superior parietal cortices and varieties of mental rotation. Trends in Cognitive Sciences, 7, 515-517.

PrICE, C. J. (2000). The anatomy of language: Contributions from functional neuroimaging. Journal of Anatomy, 197, 335-359.

Rainville, C., Marchand, N., \& Passini, R. (2002). Performances of patients with a dementia of the Alzheimer type in the Standardized Road-Map test of Direction Sense. Neuropsychologia, 40, 567-573.

Rigal, R. (1994). Right-left orientation: Development of correct use of right and left terms. Perceptual \& Motor Skills, 79, 1259-1278.

RigAL, R. (1996). Right-left orientation, mental rotation, and perspectivetaking: When can children imagine what people see from their own viewpoint? Perceptual \& Motor Skills, 83, 831-842.

SchulTz, K. (1991). The contribution of solution strategy to spatial performance. Canadian Journal of Psychology, 45, 474-491.

Shepard, R. N., \& CoOPER, L. A. (1982). Mental images and their transformations. Cambridge, MA: MIT Press.

SHEPARD, R. N., \& HuRwitz, S. (1984). Upward direction, mental rotation, and discrimination of left and right turns in maps. Cognition, 18, 161-193.

Storfer, M. D. (1995). Problems in left-right discrimination in a highIQ population. Perceptual \& Motor Skills, 81, 491-497.

Wolf, S. M. (1973). Difficulties in right-left discrimination in a normal population. Archives of Neurology, 29, 128-129.

ZACKS, J. M., \& MiCHELON, P. (2005). Transformations of visuospatial images. Behavioral \& Cognitive Neurosciences Reviews, 4, 96-118.

Zacks, J. M., Vettel, J. M., \& Michelon, P. (2003). Imagined viewer and object rotations dissociated with event-related FMRI. Journal of Cognitive Neuroscience, 15, 1002-1018.

Zaehle, T., Jordan, K., Wustenberg, T., Baudewig, J., Dechent, P., \& MAST, F. W. (2007). The neural basis of the egocentric and allocentric spatial frame of reference. Brain Research, 1137, 92-103.

(Manuscript received January 21, 2009; revision accepted for publication June 2, 2009.) 